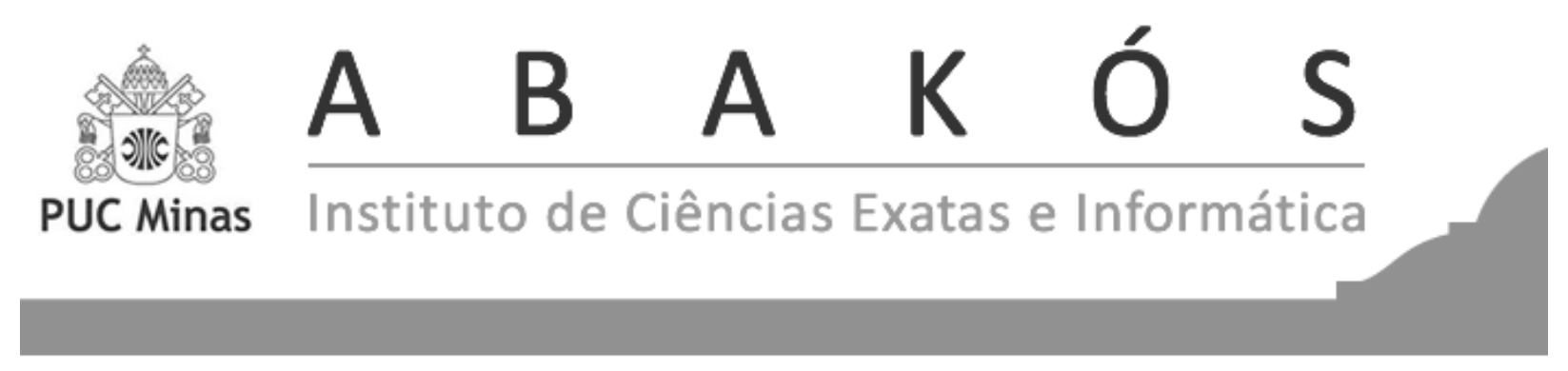

\title{
O Programa PDE ESCOLA na Rede Pública Estadual de Ensino de Minas Gerais: Uma Análise dos Desafios e Contribuições para a Gestão Pedagógica*
}

PDE ESCOLA Program at a Public State Education System of Minas Gerais, Brazil: An Analysis of the Challenges and Contributions for Pedagogical Management

Leise de Paula Reis Lima ${ }^{1}$ Suzana dos Santos Gomes ${ }^{2}$

\begin{abstract}
Resumo
O Plano de Desenvolvimento da Escola (PDE Escola) foi fortemente influenciado pelo avanço das Tecnologias Digitais da Informação e Comunicação (TDIC) e, consequentemente, sofreu alterações no decorrer de sua trajetória. Nesse sentido, o presente trabalho apresenta resultados de uma pesquisa sobre a implementação do PDE Escola na Rede Pública Estadual de Ensino de Minas Gerais (RPEE-MG). A investigação foi realizada a partir da pesquisa de campo de abordagem qualitativa, associada à pesquisa documental e bibliográfica. O objetivo do presente texto é analisar os resultados obtidos por uma das escolas mineiras priorizada pelo governo federal e a relação da gestão com a interatividade do programa na plataforma virtual do Ministério da Educação. Constatou-se que a introdução das TDIC no contexto escolar favoreceu a disseminação do PDE Escola e otimizou a elaboração do plano de ação pelos profissionais da escola pesquisada. Os resultados revelaram que o financiamento do governo federal foi descentralizado com mais celeridade, e que houve melhoria na infraestrutura física e da gestão pedagógica da escola. Espera-se que esse estudo contribua com futuras pesquisas relacionadas ao tema, como PDE Escola e TDIC, como política pública nacional de apoio à gestão.
\end{abstract}

Palavras-chave: Políticas Públicas. PDE Escola. Tecnologia Digital. Gestão Escolar.

\footnotetext{
* Submetido em 13/11/2018 - Aceito em 01/04/2019

${ }^{1}$ Mestre em Educação pela Universidade Federal de Minas Gerais - UFMG. Programa de Pós-Graduação em Educação e Docência - Promestre. Analista Educacional e Inspetora Escolar da Superintendência Regional de Educação de Ubá - SRE, Brasil - leiselimaufmg@ gmail.com

${ }^{2}$ Doutora em Educação pela Universidade Federal de Minas Gerais - UFMG. Pós-Doutora pela Universidade de Lisboa - U.L e Universidade de São Paulo - USP. Professora e Pesquisadora do Programa de Pós-Graduação em Educação e Docência e do Programa de Pós-Graduação em Educação: Conhecimento e Inclusão Social, Brasil suzanasgomes@fae.ufmg.br
} 


\begin{abstract}
The Plano de Desenvolvimento da Escola - PDE Escola [School Development Plan] was strongly influenced by the advance of Digital Information and Communication Technology (DICT) and consequently passed through modifications along its trajectory. In that sense, this work presents results from a research on the implementation of PDE Escola on the Public State Education System of Minas Gerais (RPEE-MG). The investigation was carried from a field research of qualitative approach, associated to documental research and literature review. The aim of the present text is to analyze the results achieved by the school prioritized by the Brazilian federal government and the relationship of management with the interactivity of the program on the virtual platform of Brazil's Education Ministry. We verified that the introduction of DICT's at school context favored the dissemination of PDE Escola and optimized the elaboration of the action plan by the school staff. The results showed that federal government funding was decentralized more quickly and that there was improvement in the physical infrastructure and the pedagogical management of the school. We hope that this study contributes with future research related to the theme, such as PDE Escola and DICT, as a national public policy for management support.
\end{abstract}

Keywords: Public Policies. PDE Escola. Digital Information and Communication Technology. School Management. 


\section{INTRODUÇÃO}

Este artigo apresenta uma análise sócio-histórica da implementação de uma política pública implementada pelo Ministério da Educação (MEC) intitulada Plano de Desenvolvimento da Escola (PDE Escola) mediado pelas Tecnologias Digitais da Informação e Comunicação (TDIC). A proposta visa compreender a grande expansão e consolidação dessa política educacional a partir do avanço das TDIC na educação.

O PDE Escola surgiu em 1998, em um contexto de democratização da educação e enfrentamento de altos índices de reprovação na busca pela equidade de oportunidades e melhoria da gestão em municípios mais populosos e pobres de três regiões do país, a saber: Norte, Nordeste e Centro-Oeste. O plano foi impulsionado, primeiramente, pela Declaração Mundial de Educação para Todos, realizada em 1990, em Jomtiem, na Tailândia, que concentrou atenção não só no acesso, mas também na aprendizagem e permanência dos alunos. Posteriormente, o governo federal selecionou escolas com baixo desempenho por meio do Índice de Desenvolvimento Humano (IDH) para apoiá-las financeiramente. O Índice de Desenvolvimento da Educação Básica (IDEB) foi criado em 2007 e reúne, em um só indicador, os resultados de dois conceitos igualmente importantes para a qualidade da educação: o fluxo escolar e as médias de desempenho nas avaliações.

Essa temática requer menção às contribuições teóricas que permearam a construção desse trabalho, capazes de elucidar o itinerário desse programa, desde a reforma educacional brasileira, dentre eles: Afonso (2001), Dalben (2004), Scaff (2007), Scaff (2008), Mill e Jorge (2013), Libâneo et al. (2012), e Gomes (2003), Gomes (2014), Gomes (2015).

Ainda não estavam disponíveis, naquela década de 1990, nas escolas públicas do país, computadores conectados à rede mundial de computadores (internet) e os diversos formulários eram preenchidos manualmente, enviados ao MEC via correio, e as orientações a respeito das eventuais reformulações eram dadas por telefone, ou também, via correio, o que tornava, segundo Scaff (2007), a elaboração do plano um processo bastante moroso.

No decorrer de 20 anos de trajetória, o plano foi modificado, reestruturado e potencializado pela introdução das TDIC, passando de abrangência restrita para escala nacional. É importante reiterar que o desenvolvimento do plano foi sensivelmente modificado devido ao "mundo imerso em TDIC, tecnologias que ampliam de forma, às vezes, espantosa o acesso a múltiplas fontes de informação" conforme constata Marinho (2015, p. 125).

É notória a importância da TDIC para a melhoria do acesso à informação nas instituições escolares e para a implementação de políticas públicas. Nesse sentido, passou a exigir dos gestores uma proficiência quanto ao uso de tecnologias para a implementação das políticas educacionais.

A partir de 2014, por meio dos benefícios de integração, em plataforma única, disponível no site do MEC, o Programa Dinheiro Direto na Escola (PDDE) Interativo passou a abranger outros programas para a descentralização de recursos federais, tais como o PDE Escola, Atleta na Escola, Programa Ensino Médio Inovador (ProEMI), Mais Educação, Escolas do Campo, 
Escolas Sustentáveis, e Água na Escola.

Realizou-se neste trabalho, por meio de levantamento bibliográfico, pesquisa documental sobre PDE Escola e TDIC, seguidos de pesquisa de campo realizada por meio de estudo de caso. Na pesquisa documental buscaram-se na legislação e nos documentos disponíveis no site do MEC, escolas priorizadas para receber financiamento das ações do PDE Escola, para definição da escola a ser pesquisada. Procurou-se, também, contextualizar e traçar o itinerário metodológico do PDE Escola desde a sua origem até os dias atuais, no Brasil e em Minas Gerais. A partir da pesquisa bibliográfica sobre PDE Escola, analisaram-se as produções encontradas no Banco de Teses da Comissão de Aperfeiçoamento de Pessoal do Nível Superior (CAPES) no período de 1998 a 2015, além de livros e artigos acadêmicos. Como instrumento de pesquisa, elegeu-se a aplicação de questionários aos professores, e entrevistas semiestruturadas aos especialistas e direção da escola e, por fim, utilizou-se de observação participante das reuniões pedagógicas. Optou-se pela vertente metodológica de cunho qualitativa por considerar ser a que melhor se adequa ao objetivo da investigação.

Esse contexto suscitou algumas reflexões sobre a utilização do sistema virtual do MEC e a operacionalização do Programa PDE Escola, entre elas: os gestores conseguiram operacionalizar o plano estratégico na plataforma do MEC com autonomia e segurança? O gestor conseguiu sanar dúvidas durante a inserção do Plano de Ação na plataforma?

A expansão promovida pelo MEC, quanto ao programa PDE Escola, promoveu modificações nas competências técnicas dos gestores e nas relações que permeiam o cotidiano escolar. Nesse sentido, torna-se relevante o estudo da implementação dessa política pública na escola, que estabeleceu novas relações de trabalho e de comunicação entre os profissionais da escola e o MEC.

\section{METODOLOGIA DO PDE ESCOLA: EVOLUÇÃO DOS PROCESSOS DE GESTÃO E PROCEDIMENTOS DOS MANUSCRITOS AOS DIGITAIS}

Esta seção, organizada em duas partes, tem como objetivo apresentar, primeiramente, um levantamento da literatura sobre a Reforma Educacional Brasileira, a influência de Organismos Internacionais como o Banco Mundial (BM) nas políticas públicas, a origem e princípios do PDE Escola. Em seguida, apresenta-se a metodologia do PDE Escola, com ênfase no avanço das TDIC e da Avaliação, considerados marcos referenciais para a operacionalização do plano.

\subsection{ORIGEM E PERCURSO DO PDE ESCOLA}

O MEC lançou o PDE Escola em 1998, como mecanismo de fortalecimento da autonomia da escola, por meio de um processo de autoavaliação, e a elaboração de um plano de ações, concebido no âmbito do Fundo de Desenvolvimento da Escola (FUNDESCOLA), em 
cooperação técnico financeira entre o governo brasileiro e o BM.

Segundo Scaff (2008, p. 574), havia “um manual de 200 páginas com orientações sobre o período em que se realiza cada reunião, o que se faz com cada uma delas, bem como os responsáveis para cada uma das ações".

$\mathrm{O}$ atendimento era feito, exclusivamente, às escolas públicas de Ensino Fundamental localizadas nas Zonas de Atendimento Prioritário (ZAP's) das regiões Norte, Nordeste e CentroOeste do país, escolhidas entre aquelas com baixo IDH, e a descentralização dos recursos financeiros era realizada, via PDDE. Pode-se afirmar que a abrangência era restrita pela limitação na comunicação do governo federal e as escolas, como também, pelo índice de referência utilizado na época.

Houve, em 2007, o lançamento do Plano de Desenvolvimento da Educação (PDE) que marcou a história do PDE Escola, com: a criação do IDEB, que se tornou a referência do MEC, para a definição de escolas que receberiam o financiamento desse plano de ação, em substituição ao IDH; e a criação de um sistema virtual, on-line, denominado, em 2009, Sistema Integrado de Monitoramento, Execução e Controle (SIMEC), posteriormente, em 2012, PDE Interativo e, em 2014, PDDE (Programa Dinheiro Direto na Escola) Interativo.

Estudos realizados por Lima (2017), demonstram que o advento da internet favoreceu a expansão da implementação do PDE Escola nacionalmente porque: permitiu assessoramento dos técnicos do MEC às escolas por meio de uma plataforma virtual; potencializou os dados estatísticos; facilitou a visualização e a priorização dos desafios a serem enfrentados pela escola. Certamente, representando um grande avanço na implementação dessa política pública educacional.

\subsection{METODOLOGIA DE GESTÃO DO PDE ESCOLA}

Para melhor compreender a metodologia utilizada pelo PDE Escola propõe-se a observação da estrutura, constante na Figura 1 com a representação gráfica do PDE Escola. 
Figura 1 - Representação gráfica do PDE Escola

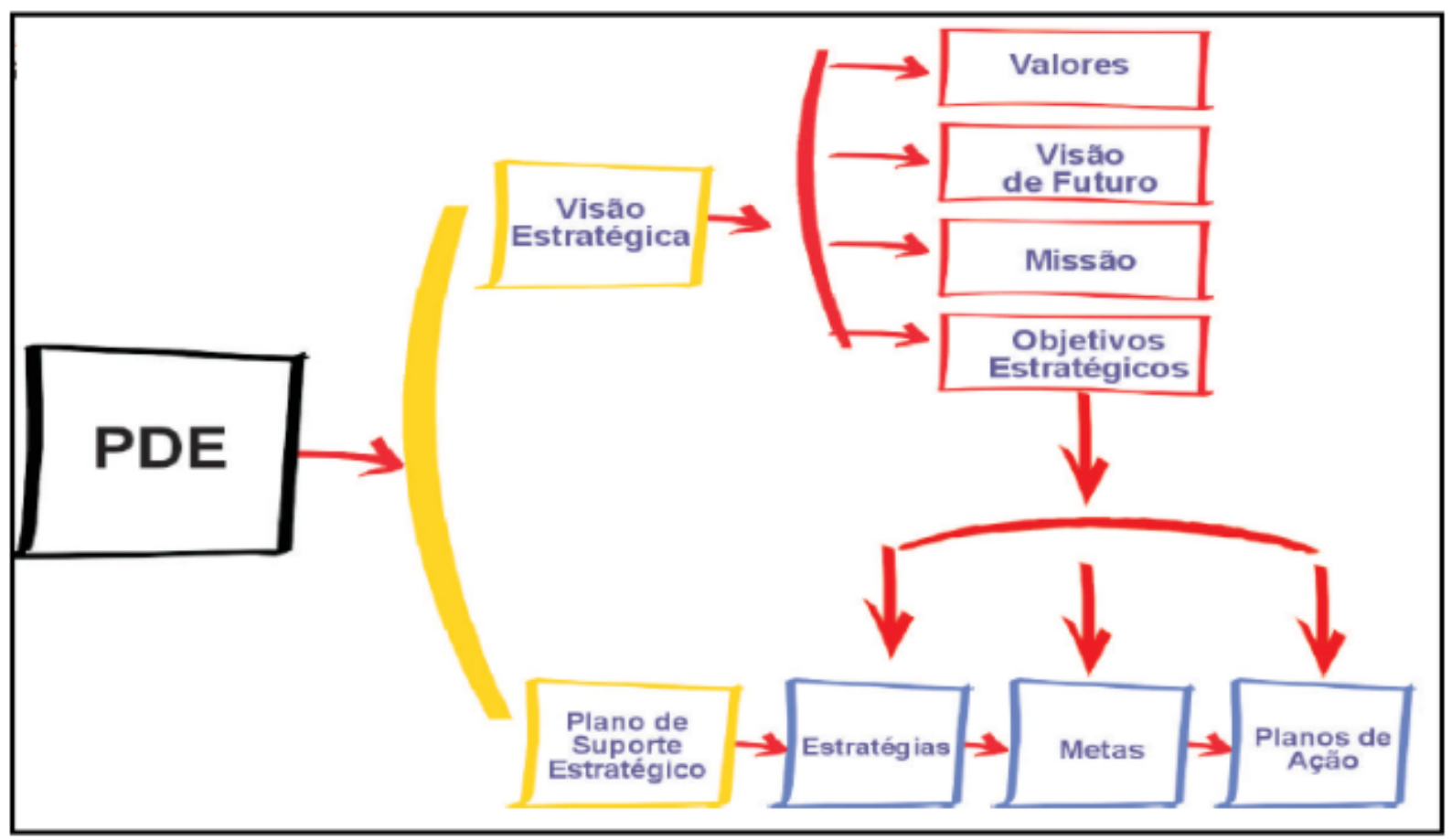

Fonte: Brasil (2006)

De acordo com as orientações contidas no manual (BRASIL, 2006) na etapa de autoavaliação, análise situacional ou diagnóstico para realização do levantamento sistemático de dados e informações sobre a qualidade da escola em seus diferentes aspectos, eram organizadas três fichas que antecedem a fase de elaboração do Plano de Suporte Estratégico.

A primeira ficha corresponde ao Instrumento 1 do manual, que contém levantamento do Perfil e Funcionamento da Escola (PFE). A elaboração do plano de ação demandava grande esforço dos profissionais da escola, que faziam parte do comitê estratégico, na elaboração do diagnóstico, pois, a coleta dos dados estatísticos, como número de professores, alunos, por turno, indicadores de desempenho por turma, turno e disciplina, recursos recebidos para desenvolvimento de projetos, fontes de recursos, infraestrutura, relação com a comunidade, entre outros, era feita manualmente.

Em seguida, o Instrumento 2 apresenta critérios considerados determinantes para o sucesso escolar, organizados em: ensino-aprendizagem, clima escolar, pais e comunidade, gestão de pessoas, gestão de processos, infraestrutura e resultados. O Instrumento 3 corresponde à avaliação da escola e às variáveis internas e externas à escola.

A partir desse diagnóstico discutido e bem elaborado, propõe-se a elaboração do Plano de Ação e, com isso, atingir os objetivos propostos.

Após as etapas anteriores, os formulários eram enviados ao MEC, via correio e as orientações a respeito das eventuais reformulações eram dadas por telefone, ou, também, via correio. Após a aprovação do PDE Escola, o financiamento era descentralizado à escola, via Plano de Melhoria da Escola (PME), responsável por financiar as ações prioritárias definidas no plano.

Com a expansão das TDIC e o lançamento do PDE, os programas educacionais elabo- 
rados pelo MEC foram gradativamente sendo disponibilizados em ambientes virtuais.

Em 2009, embora ainda, com uma abrangência restrita, o MEC criou o Sistema Integrado de Monitoramento, Execução e Controle (SIMEC), por meio de tecnologia on-line, definido como

sistema que pode ser acessado de qualquer computador que esteja ligado à rede mundial de computadores (internet). [...]. A elaboração do PDE Escola e o posterior acompanhamento do seu trâmite são feitos no SIMEC, onde serão disponibilizadas outras informações importantes para o município. (BRASIL, 2008, p. 6).

Para acesso ao sistema, os diretores das escolas estaduais eram cadastrados por meio do Cadastro de Pessoa Física (CPF) e a senha disponibilizada via e-mail institucional por um grupo constituído, no âmbito da Secretaria Estadual de Educação de Minas Gerais, denominado Comitê Estadual da SEE-MG.

O referencial para seleção das escolas para receber o financiamento das ações do PDE Escola passou do IDH para o IDEB. Ainda assim, as regiões do Nordeste, Norte e Centro-Oeste foram as regiões do Brasil que mais necessitavam de ações de melhoria do governo federal, sinalizando que as condições socioeconômicas das famílias, da escola e da comunidade podem interferir diretamente nos resultados de aprendizagem dos alunos.

Em 2012, após revisão do SIMEC, a metodologia do PDE Escola foi utilizada na construção do sistema on-line denominado PDE Interativo. Dessa vez, universalizado para todas as escolas públicas do país, independentemente do recebimento de recursos federais do PDE Escola (BRASIL, 2012).

A universalização desse sistema on-line integrou outras bases de dados do MEC, tais como, os dados do Censo Escolar, por meio do EDUCACENSO, "um sistema de coleta de dados que pretende efetuar levantamento de dados pela internet, abrangendo de forma individualizada, cada estudante, professor, turma e escola do país" (SAVIANI et al., 2007, p. 1235), e do Instituto Nacional de Estudos e Pesquisas Educacionais Anísio Teixeira (INEP) com as proficiências dos alunos na Prova Brasil e o IDEB, para otimização do trabalho que até então era considerado moroso pelos pesquisadores e significou dar oportunidade a cerca de 160 mil escolas públicas no Brasil na utilização de uma tecnologia de gestão, baseada em planejamento estratégico, mediado pelas TDIC.

A partir de 2014, houve alteração no sistema PDE Interativo, que passou a denominar-se PDDE Interativo, conforme mostra a Figura 2, que contém a primeira tela exibida ao acessar o sistema do PDDE Interativo estruturado em: Identificação, Primeiros passos, Diagnóstico e Plano Geral. 
Figura 2 - Estrutura do PDE Escola no sistema PDDE Interativo

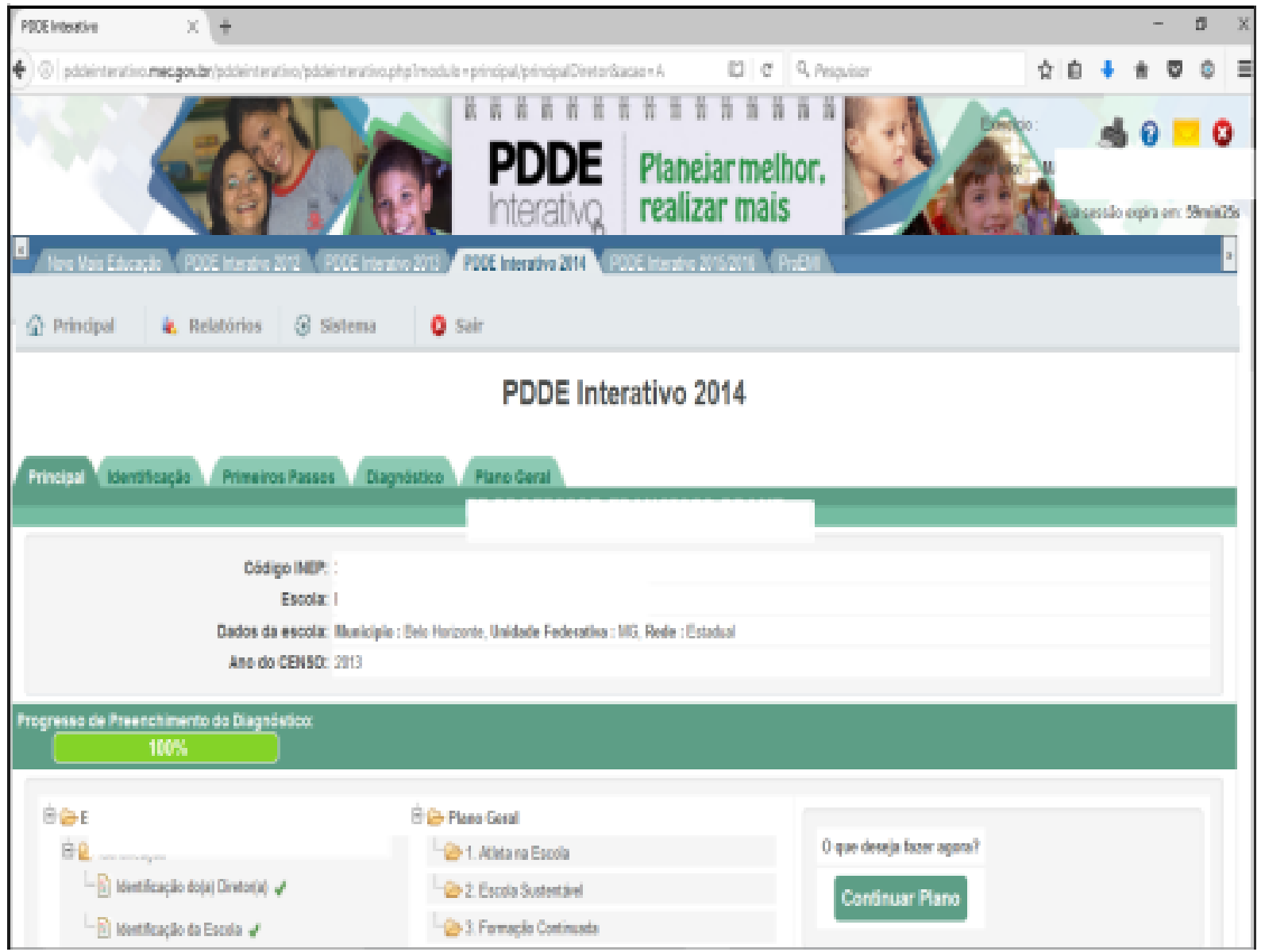

Fonte: Brasil (2012).

Depreende-se, a partir desse breve relato histórico, mostrar que houve aprimoramento do PDE Escola, como tecnologia de gestão mediada pelas TDIC, independente do financiamento de ações para melhoria da gestão e das práticas pedagógicas e como política pública nacional, pois sua metodologia passou a ser utilizada para orientar programas de melhoria das práticas pedagógicas de todas as etapas de ensino da educação básica.

A comunicação entre as esferas federal e estadual e a direção da escola é quase imediata, dentro do próprio sistema virtual. A entrada da internet nas unidades escolares, proporcionou "outras possibilidades de comunicação, e, com isso, as fronteiras territoriais ficaram menos palpáveis e o espaço e o tempo foram reconfigurados" (MILL; JORGE, 2013, p. 42), o que se pode converter em mais benefícios tecnológicos contemporâneos. Houve redução do tempo de aprovação e monitoramento das ações da escola pelo MEC, uma vez que toda e qualquer alteração realizada pela escola é acompanhada por técnicos do MEC em tempo real.

Ressalta-se que, por serem caracterizados pelo MEC como interativos, não houve formação do MEC, da SEE e da SRE para operacionalização dos programas e todos os materiais de orientação foram disponibilizados na plataforma do MEC e enviados via e-mail institucional.

Para o desenvolvimento do PDE Escola, foram definidos grupos de trabalho ou comitês, conforme Figura 3, abrangendo profissionais em âmbito federal, estadual, regional com definição de atribuições específicas a serem desenvolvidas, a fim de contribuir para que o pla- 
nejamento fosse bem organizado.

Figura 3 - Estrutura do PDE Escola no sistema PDDE Interativo

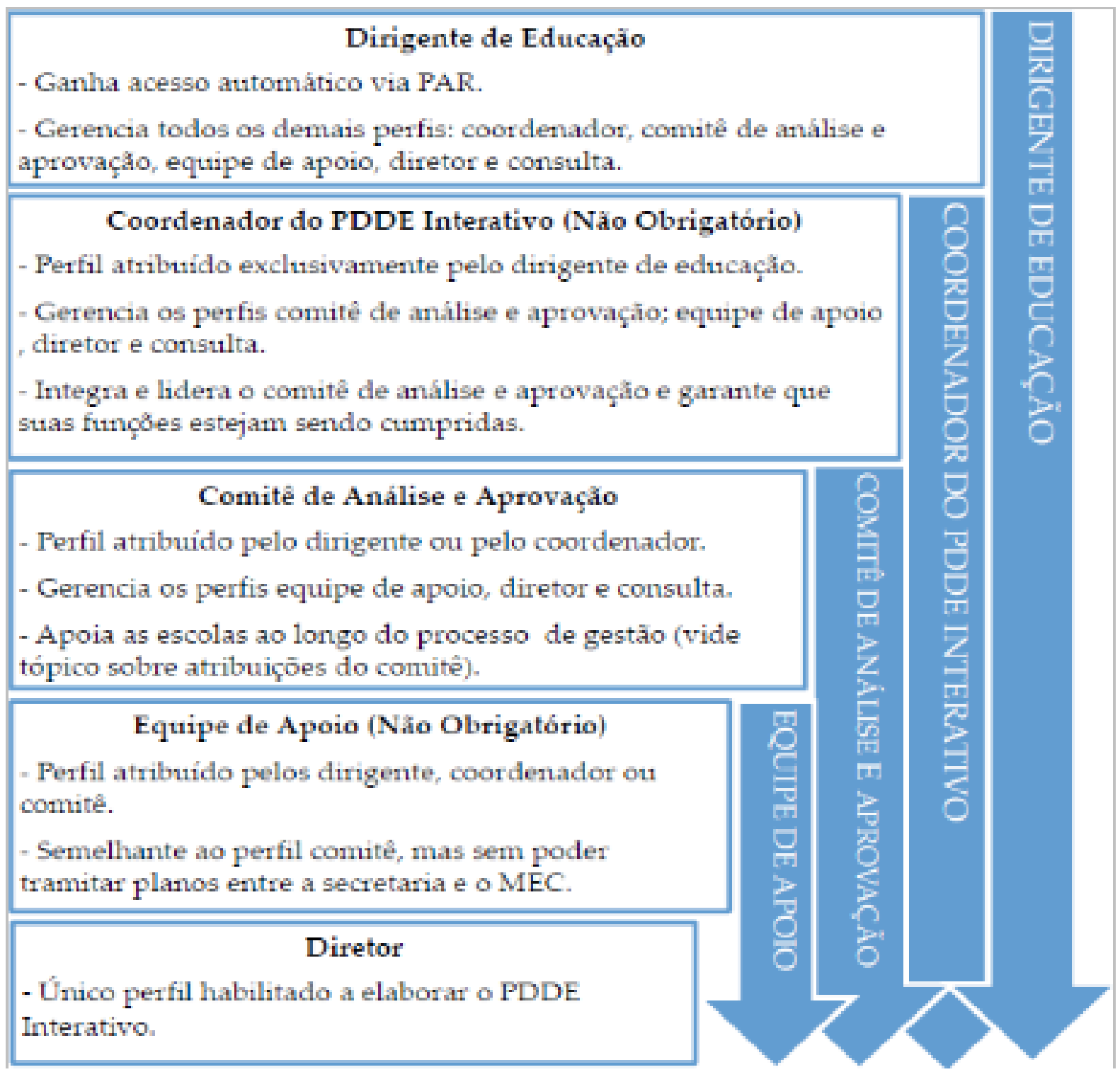

Fonte: Brasil (2014).

Nesse contexto, pode-se afirmar, em outras palavras, que essa ferramenta interativa proporcionou aos gestores mais tempo para reflexão sobre seus resultados educacionais, proposição de alternativas coerentes, aprimoramento profissional e, por conseguinte, maiores chances de alcançar o objetivo de melhorar a qualidade da educação básica.

Segundo Lima (2017, p. 59) a partir da análise desse contexto, conclui-se que

as práticas e os hábitos dos gestores foram modificados e que o computador e a internet trouxeram novas formas de acesso à informação, novas formas de conhecimento, novas maneiras de interação entre os órgãos e implementação de políticas públicas. 


\section{RESULTADOS E DISCUSSÕES}

Nesta seção propõe-se apresentar os resultados e propor algumas discussões sobre o estudo de caso realizado em uma escola da rede estadual de ensino de Minas Gerais, localizada em Belo Horizonte, selecionada pelo MEC para desenvolver o PDE Escola no ano de 2012, com financiamento. O referido plano de ação encontra-se disponível para consulta pública no site do MEC1. A Escola Estadual Miguel Brandão2 (EEMB) foi selecionada para receber financiamento do governo federal em 2012 devido aos baixos resultados no IDEB no ano de 2009 e 2011 conforme pode ser observado na Tabela 1.

Tabela 1 - Resultado do IDEB EEMB - Anos Finais do Ensino Fundamental

\begin{tabular}{c|c|c|c|c|c|c|c|c|c|c|c|c}
\hline \multicolumn{4}{c|}{ IDEB observado } & \multicolumn{8}{c}{ Metas projetadas } \\
\hline 2005 & 2007 & 2009 & 2011 & 2013 & 2007 & 2009 & 2011 & 2013 & 2015 & 2017 & 2019 & 2021 \\
\hline 3,6 & 4,3 & 3,0 & 1,9 & 3,5 & 3,6 & 3,7 & 4,0 & 4,4 & 4,8 & 5,1 & 5,3 & 5,6 \\
\hline
\end{tabular}

Fonte: Portal do IDEB (2016).

Para reverter esse cenário de exclusão e fracasso educacional, o plano foi elaborado pela escola e continha 18 estratégias e 24 ações, devidamente detalhadas, distribuídas entre 10 profissionais que se responsabilizaram pela sua execução. A escola recebeu recurso no valor de $\mathrm{R}$ \$ 64.500,00, sendo R \$ 45.150,00 para aquisição de itens de custeio e R\$ 19.350,00 para materiais de capital, descentralizado via PDDE, diretamente à Unidade Executora (UEx) da escola. Esse valor foi definido pelo governo federal, considerando o número de alunos da escola, no caso 1031 alunos, obtido por meio do Censo Escolar 2012, que define os critérios de priorização da escola.

O sistema interativo promoveu a integração da base de dados quanto ao número de alunos e dos resultados obtidos nas avaliações internas (fluxo escolar) e externas (Prova Brasil), promovendo maior tempo para os profissionais da escola refletirem quanto às ações a serem propostas para melhoria educacional.

De acordo com o depoimento do Professor de Filosofia, um dos protagonistas da elaboração do PDE Escola na EEMB, juntamente com a equipe gestora, houve assessoramento da Analista Educacional da Superintendência Regional de Ensino (SRE) - Metropolitana B, de Belo Horizonte, no acesso ao sistema virtual do MEC. Esse apoio facilitou a operacionalização do Programa PDE Escola, promovendo autonomia e segurança no uso do sistema interativo do MEC.

Observou-se, à época da pesquisa, nos momentos de observação participante, reuniões pedagógicas e conselhos de classe, que a prática da educação inclusiva começou a ser discutida para implementação do PDE Escola. Nas reuniões pedagógicas, observou-se diferentes concepções de avaliação, alguns defendiam a concepção formativa, diagnóstica, contínua e emancipatória e outros, optaram por uma concepção tradicional, focalizando a reprodução do conteúdo em sala de aula.

Pode-se afirmar que a apropriação dos resultados da avaliação utilizados para diagnosti- 
car de modo contínuo, formativo e emancipatório é considerada a mais indicada para atender as demandas da escola, que exige grande energia do professor e "disponibilidade de tempo que vai muito além do tempo das aulas, sendo necessária elaboração de estratégias adequadas e, com frequência, individualizadas a realizar" (AFONSO, 2001, p. 92).

Trata-se de uma prática de avaliação que propõe reflexão contínua do processo ensinoaprendizagem em um contexto marcado pela diversidade cultural e, portanto, demanda compromisso com a inclusão, com a pluralidade e respeito às diferenças. (GOMES, 2014).

O sistema interativo contribuiu, por meio da migração de banco de dados do MEC e do INEP, para que os profissionais da escola conhecessem o caminho percorrido ao longo dos anos e assim, possibilitou uma reflexão profunda de seus resultados e seu contexto atual, com a otimização do tempo que, até então, era utilizado na coleta de dados manualmente.

Verificou-se, por meio da observação participante que houve um melhor aproveitamento do tempo para análise e reflexão das práticas pedagógicas e das concepções adotadas quanto às avaliações no cotidiano escolar. Além disso, identificou-se maior investimento na infraestrutura da escola e, na manutenção de equipamentos dos laboratórios de ciências e de informática. Essas mudanças promoveram maior aproveitamento do espaço físico da escola, redução de grades internas e aumento dos espaços de convivência para os alunos.

Os resultados apresentados na Tabela 1 revelam que, embora a escola não tenha atingido a meta de 4,4 projetada pelo MEC, houve melhorias no desempenho escolar no ano de 2013, pois a escola alcançou o percentual de 3,5 superando o resultado de 1,9 no ano de 2011. Outra consideração pertinente, refere-se ao fato de não se poder atribuir mérito somente ao PDE Escola pela melhoria desses resultados, uma vez que outros projetos também foram desenvolvidos concomitantemente.

\section{CONSIDERAÇÕES FINAIS}

Diante do exposto nesse artigo, conclui-se que o PDE Escola, política pública nacional de apoio à gestão escolar, em seus 20 anos de implementação, foi fortemente influenciado pelo avanço das TDIC, potencializou dados estatísticos, promoveu maior compreensão dos desafios a serem enfrentados pelos gestores e pela comunidade escolar. Sua relevância está na possibilidade de tornar a escola um espaço cada vez mais democrático, participativo e de reflexão.

O sistema interativo implementado dinamizou a elaboração do PDE Escola e aprimorou o sistema de comunicação entre a escola e os respectivos órgãos. Espera-se que os profissionais da educação utilizem os resultados desta pesquisa para melhor direcionarem seus projetos, não só o PDE Escola e que, além disso, utilizem o planejamento como uma política educacional de gerenciamento responsável de recurso público e que promova maior qualidade da educação pública. 


\section{REFERÊNCIAS}

AFONSO, Almerindo Janela. Escola pública, comunidade e avaliação: resgatando a avaliação formativa como instrumento de emancipação. Avaliação: uma prática em busca de novos sentidos, DP \& A Rio de Janeiro, v. 2, p. 83-99, 2001.

BRASIL, MEC. Como elaborar o Plano de Desenvolvimento da Escola: aumentando o desempenho da escola por meio do planejamento eficaz. 3. ed. Brasília: FUNDESCOLA/DIPRO/FNDE/MEC, 2006. Disponível em: <ftp://ftp.fnde.gov.br/web/fundescola/publicacoes_ manuais_tecnicos/pde_escola.pdf $>$.

BRASIL, MEC. PDE Escola-SIMEC. Orientações sobre preenchimento do cadastro. Brasília: [s.n.], 2008. Disponível em: <http://portal.mec.gov.br/index.php?option=com_docman\& view $=$ download $\&$ alias=433-cadastro-pdeescola\&Itemid=30192>. Acesso em: 10 jun. 2015.

BRASIL, MEC. Manual do PDE Interativo. [s.n.], 2012. Disponível em: < http://pdeescola. mec.gov.br/images/stories/pdf/pdeinterativo_manual_junho2012.pdf $>$. Acesso em: 10 maio 2015 .

BRASIL, MEC. Manual do PDE Interativo. [s.n.], 2014. Disponível em: <http://pdeescola. mec.gov.br/images/stories/pdf/manual_pdde_interativo_2014.pdf>. Acesso em: 10 maio 2015.

DALBEN, Angela Imaculada Loureiro de Freitas. Conselhos de classe e avaliação: perspectivas na gestão pedagógica da escola. Campinas, SP: Papirus Editora, 2004.

GOMES, Suzana dos Santos. Tessituras Docentes da Avaliação Formativa. 2003. 213 f. Dissertação (Mestrado em Educação) - Faculdade de Educação, Universidade Federal de Minas Gerais, Belo Horizonte, MG.

GOMES, Suzana dos Santos. Um olhar sobre as práticas de avaliação na escola. Belo Horizonte, MG: Mazza Edições, 2014.

GOMES, Suzana dos Santos. Políticas de avaliação externa e interna: Desafios e perspectivas. In: GOMES, Suzana dos Santos; QUARESMA, Adilene Gonçalves (org.). Políticas e Práticas na Educação Básica e Superior: Desafios da contemporaneidade. Belo Horizonte: Fino Traço, 2015. p. 347-360.

LIBÂNEO, J; OLIVEIRA, JF; TOSCHI, MS. Educação escolar: políticas, estrutura e organização. 10. ed. São Paulo: Cortez, 2012.

LIMA, L. P. R. O Programa PDE Escola na rede pública estadual de ensino de Minas Gerais: uma análise dos desafios e contribuições para a gestão pedagógica. 2017. 188 f. Dissertação (Mestrado) - Faculdade de Educação, Universidade Federal de Minas Gerais, Belo Horizonte. Disponível em: <http://www.bibliotecadigital.ufmg.br>. Acesso em: 10 set. 2017.

MARINHO, S. P. P. Sala de aula descentrada: As tecnologias digitais de informação e comunicação para uma inovação de ruptura na formação inicial de professores. In: GOMES, Suzana dos Santos; QUARESMA, Adilene Gonçalves (org.). Políticas e Práticas na Educação Básica e Superior: Desafios da contemporaneidade. Belo Horizonte: Fino Traço, 2015.

MILL, Daniel; JORGE, Gláucia. Sociedades grafocêntricas digitais e educação: sobre letramento, cognição e processos de inclusão na contemporaneidade. In: MILL, Daniel (org.). Escritos sobre Educação: desafios e possibilidades para ensinar e aprender com as tecnologias emergentes. São Paulo: Paulus, 2013. p. 39-71. 
SAVIANI, Dermeval et al. O plano de desenvolvimento da educação: análise do projeto do mec. Educação \& Sociedade, Centro de Estudos Educação e Sociedade-Cedes, Campinas, v. 28 , n. 100, p. 1231-1255, 2007. Disponível em: <http://www.cedes.unicamp.br>. Acesso em: 10 maio 2015.

SCAFF, Elisângela Alves da Silva. Planejamento da educação e cooperação internacional: uma análise dos programas Monhangara e Fundescola. 2007. 255 p. Tese (Doutorado) - Faculdade de Educação, Universidade de São Paulo, São Paulo, SP. Disponível em: $<w w w . t e s e s . u s p . b r / t e s e s>$. Acesso em: 10 out. 2015.

SCAFF, Elisângela Alves da Silva. Planejamento da educação: orientação global x ação local. Perspectiva, Florianópolis, v. 26, n. 2, p. 571-592, 2008. Disponível em: <www.perspectiva. ufsc.br>. Acesso em: 01 out. 2015. 